\title{
Molecular Evolution of piRNA and Transposon Control Pathways in Drosophila
}

\author{
C.D. Malone AND G.J. HANNON \\ Watson School of Biological Sciences, Howard Hughes Medical Institute, \\ Cold Spring Harbor Laboratory, Cold Spring Harbor, New York 11724 \\ Correspondence: hannon@cshl.edu
}

\begin{abstract}
The mere prevalence and potential mobilization of transposable elements in eukaryotic genomes present challenges at both the organismal and population levels. Not only is transposition able to alter gene function and chromosomal structure, but loss of control over even a single active element in the germline can create an evolutionary dead end. Despite the dangers of coexistence, transposons and their activity have been shown to drive the evolution of gene function, chromosomal organization, and even population dynamics (Kazazian 2004). This implies that organisms have adopted elaborate means to balance both the positive and detrimental consequences of transposon activity. In this chapter, we focus on the fruit fly to explore some of the molecular clues into the long- and short-term adaptation to transposon colonization and persistence within eukaryotic genomes.
\end{abstract}

\section{TRANSPOSON OCCUPATION IN EUKARYOTIC GENOMES}

Transposable elements, or transposons, are selfish genetic elements that possess the ability to mobilize within a genome, potentially causing serious damage. They can accomplish this through several well-understood mechanisms. Most move via an RNA intermediate (class I: retrotransposons), whereas others colonize new locations through the direct transfer of transposon DNA (class II: DNA transposons) (for review, see Slotkin and Martienssen 2007). In the case of retrotransposons, active elements within the genome are transcribed and translated into functional proteins that subsequently generate an additional DNA copy of the element and catalyze its integration into a new genomic site. DNA transposons are also transcribed and translated into proteins that instead excise a physical DNA copy of an element from the genome and then insert that DNA elsewhere in the genome. This "cut-and-paste" mechanism generates no net increase in copies of the element on an individual level (although small genomic lesions are left behind), whereas retrotransposition actively increases transposon copy number within an individual genome. In both cases, transposon mobilization can have positive and negative consequences for the viability of an organism and its progeny, notably on the organization of its genome.

The potential detrimental effects of unregulated transposon activity are obvious. For example, by inserting into an essential gene, especially one with a sensitive dosage requirement, a transposon could severely alter cell or organismal viability. The impact of landing in a nonessential gene is less dramatic, but such events can still generate clear phenotypic manifestations (Demerec 1926a,b). Transposition into important gene regulatory regions, such as splicing regulators or transcriptional enhancer domains, could significantly change transcriptional and posttranscriptional gene expression programs (White et al. 1994). Moreover, transposons can promote alterations in chromosomal structure by generating double-stranded DNA breaks that can precede the formation of unstable dicentric and acentric chromosomes (McClintock 1950) and induce other spurious chromosomal aberrations. Finally, important chromatin domains, such as insulator and boundary elements, can be interrupted, leading to a general transcriptional misregulation in the surrounding genomic space.

Not all instances of transposon mobilization necessarily lead to such negative consequences for an organism. In fact, transposons are capable of positively influencing genomic content, structure, and evolution (Kazazian 2004). For instance, transposon movement can lead to the gain or loss of introns and exons, generating novel transcriptional output. They can also generate additional coding information in the genome, either being themselves domesticated as components of host transcripts (Miller et al. 1992; Baudry et al. 2009) or by inducing duplication of endogenous genes (Esnault et al. 2000). Transposon-induced reorganization of large chromosomal tracts can drive substantial genome-scale evolution, assuming creation of a positive selective advantage. Likewise, reorganization of transcriptional regulatory regions can drive the evolution of expression programs through either disruption or donation of novel regulatory elements. Finally, transposon-induced chromatin state changes can modify the genomic landscape by producing new broadscale regulatory domains, perhaps creating variation by altering the transcriptional output at particular developmental stages. Each of these types of events can provide substrates for evolutionary selection and thus have profound impacts on the adaptability of the organism. 


\section{Transposable Element Diversity and Challenges to Their Control}

Transposon occupation in eukaryotic genomes varies at nearly every definable level. First, the total percentage of transposon-derived DNA in a genome can range from just a few percent to more than $90 \%$. Although there is no strict correlation between organismal "complexity" and transposon load, there are certainly dramatic consequences to an organism's genomic complexity and capacity for rapid evolution. Second, element diversity varies enormously, ranging from only a few classes in organisms such as yeast and mouse to upward of 150 in the fruit fly. Again, this does not necessarily relate to phenotypic "complexity," but it could simply reflect waves of transposon challenge and fixation within wild populations. Individual transposon families possess particular transcriptional profiles, honed to maximize their propagation in germ cells and hence expansion in populations. Increased transposon diversity could also reflect the availability of multiple cellular niches, developmental stages, or tissue types that may offer some opportunity to evade control mechanisms. Third, despite their shared imperative to propagate, different transposons, even within the same element class, can be quite dissimilar in their DNA sequence composition. Therefore, to silence the diversity of element structures and sequences, cells must exploit a unified feature of transposons as a means for selective targeting.

The challenge from potentially active elements and their representation versus inactive remnants can also vary dramatically between organisms. In Drosophila, some elements have expanded to more than 50 active copies (roo has 58 in the sequenced strain genome), whereas for others, only one or even no active copies may be present (Kaminker et al. 2002). From an adaptive perspective, this may reflect the degree to which an organism has brought a particular element under control. For instance, although there are approximately eight active $I$-element copies in the sequenced Drosophila genome, there are roughly three times the amount of diverged, fragmented copies scattered throughout heterochromatic regions of the genome (Kaminker et al. 2002; Brennecke et al. 2008). This is consistent with a hypothesis that an expansion of heterochromatic fragments contributed to the ability of the cell to effectively silence active elements, but it is equally possible that insertions are simply better tolerated in these genepoor regions. In support of the former hypothesis, transposition of a single, truncated copy of the Drosophila $\mathrm{P}$ element into a repetitive telomeric locus is sufficient to induce the silencing of any additionally introduced active copies (Ronsseray et al. 1991, 1998; Marin et al. 2000). For many elements, maintenance of heterochromatic copies, even in the absence of active elements, preserves the ability to silence, indicating a selective pressure to retain these often truncated fragments (Pélisson et al. 2007). However, additional work is required to investigate a more generalizable relationship between the control of elements and the number of active and fragmented transposon copies, because they do not appear to correlate universally (Kaminker et al. 2002).
All of these complexities challenge the cell at many levels to build an effective and adaptive silencing program. However, the molecular and evolutionary mechanisms used by the cell to successfully regulate transposon activity have begun to yield a molecular understanding during the past several years.

\section{THE ADAPTATION OF TRANSPOSON CONTROL}

On the basis of their variety alone, transposable elements present an imposing threat to a cell and its genome. In Drosophila, there are $\sim 150$ different element types, each with unique expression, replication, and mobilization strategies. These also possess an astounding array of sequence-level diversity. Therefore, cells must adopt a strategy of control that relies on features shared by all transposons - one being that at some point, all active elements, regardless of their type or abundance, propagate by moving to new locations in the genome. Moreover, all encode proteins essential for their mobility (or parasitize other transposons). Thus, transposon-encoded RNAs (Fig. 1) are a logical target for control by posttranscriptional gene silencing.

\section{Small RNA-based Pathways of Transposon Regulation}

Essentially, the RNA interference (RNAi) pathway uses 20-30-nucleotide RNAs, termed small RNAs, as guides to target larger genic, repeat, or virally derived RNA molecules. At the heart of RNAi lies an Argonaute protein that binds small RNAs and uses them as a guide to either "slice" homologous RNA transcripts, bind to and inhibit their translation, or target repression by chromatin-level changes (Hannon 2002; Reinhart and Bartel 2002; Volpe et al. 2002; Malone and Hannon 2009). These silencing effects are often potent and have been shown to be essential for processes such as stem cell maintenance (Cox et al. 1998, 2000) regulating developmental progression (Houwing et al. 2007, 2008), and they are even altered in the development of some types of cancers (Gilbert et al. 2002; Symer et al. 2002; Belgnaoui et al. 2006). To accomplish these tasks, the cell must actively generate the small RNAs used to direct the activity of Argonaute proteins. Two broad biogenesis pathways for small RNAs have emerged from work of the past decade. The best understood uses RNase III-family enzymes, Dicer and/or Drosha, to generate small RNAs from double-strand substrates. However, there are clearly Dicer- and Droshaindependent mechanisms for creating small RNAs that flow into Argonaute proteins.

Germline cells have a special need to protect their genome, because this copy must faithfully transmit genetic information to offspring. Therefore, animals have developed elaborate means to adapt to the ever-changing threats to the integrity of germ-cell genomes. As in other cells of the body, a key to germline transposon regulation comes by way of RNAi (Aravin et al. 2001). However, the 


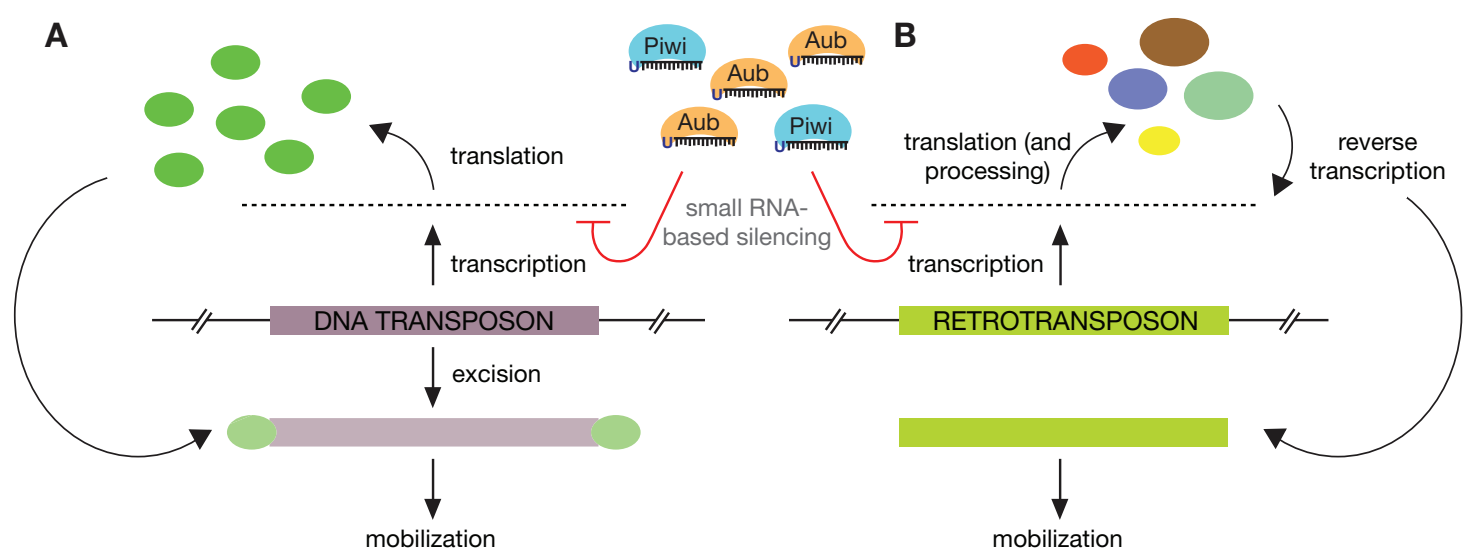

Figure 1. RNA-based targeting of transposable elements. Transposon expression, regardless of type, generates a universal target for the RNAi machinery. (A) DNA transposons are transcribed and then translated to generate a transposase enzyme capable of catalyzing the excision and cis or trans mobilization via this "cut-and-paste" mechanism. The initial transcription of the locus provides a target for silencing. $(B)$ Retrotransposons are transcribed both to be translated (non-LTR retrotransposon proteins are further posttranslationally processed) and also to serve as the substrate for reverse transcriptase to manufacture additional transposon copies. Here, either transcription products or reverse transcription substrate molecules serve as the target of the RNAi machinery.

canonical Argonaute protein was shown to be dispensable for this regulation, whereas instead, members of a separate clade of Argonautes, termed Piwi proteins and composed of Piwi, Aubergine, and AGO3 in Drosophila, had an essential role (Vagin et al. 2006). Piwi proteins bind a larger (23-32 nucleotides) class of small RNA than do canonical pathway Argonautes. These RNAs were initially termed rasiRNAs (for repeat-associated small interfering RNAs), based on their similarity to repeat elements (Aravin et al. 2001, 2003) and subsequently dubbed Piwiinteracting RNAs, or piRNAs (Aravin et al. 2006; Girard et al. 2006; Lau et al. 2006) based on their protein interaction patterns. Interestingly, piRNA production did not depend on the activity of a dicer enzyme, but instead appeared dependent on the RNA slicing activity of the Piwi proteins themselves (Vagin et al. 2006).

These observations led to a model of piRNA biogenesis that, like dicer-based pathways, requires sense and antisense RNA transcripts. However, these appear to be required in trans as single-stranded RNA, and not doublestranded RNA precursors, as seen in canonical RNAi pathways. Here, active transposon RNAs are recognized by a Piwi protein (mainly Aubergine in Drosophila), bound with a near-perfect, reverse-complementing antisense piRNA. This Piwi protein then cleaves the transposon RNA 10 nucleotides distal to the $5^{\prime}$ end of its bound piRNA (Elbashir et al. 2001). The sliced transcript is then further processed by an as yet defined machinery to generate the $3^{\prime}$ end of a new piRNA. This sense-piRNA is then loaded into the Argonaute3 (AGO3) protein (in Drosophila), which then targets antisense transposon transcripts in the cell for cleavage (Li et al. 2009). After slicing and again further processing, a new antisense piRNA is produced and loaded back into Aubergine to further target active transposon transcripts. This feed forward amplification cycle, called piRNA "ping-pong," shapes the population of piRNAs, optimizing control of expressed elements (Brennecke et al. 2007; Gunawardane et al. 2007).
In considering such a cycle, a major question is the source of the antisense transposon information. Because heterochromatic transposon fragments had been previously linked to active transposon silencing (Simonelig et al. 1988; Dimitri and Bucheton 2005), this seemed to be a logical starting point from which to investigate the origin of antisense transcripts. In fact, many fragments do not exist as isolated truncated transposons, but instead sit within what appear as transposon "graveyards," containing countless nested transposon fragments, most of which have accumulated significant mutations, leaving them otherwise inert (Brennecke et al. 2007). On the basis of sequence divergence, these loci were demonstrated to produce abundant piRNAs and were therefore termed "piRNA clusters." These are typically, although not exclusively, transcribed in both orientations as long RNA transcripts (Malone et al. 2009) that are parsed into small RNAs. In the case of pingpong, cluster-derived transcripts are proposed to serve as the source of antisense transposon content, after slicing by Piwi proteins harboring sense piRNAs (Brennecke et al. 2007; Gunawardane et al. 2007). Although the transcriptional regulation of piRNA clusters is not well understood, it appears that at least double-strand cluster transcription may be triggered by a specialized HP1 homolog, Rhino (Klattenhoff et al. 2007). Regardless, many interesting questions remain about the selection of RNA transcripts to feed the transposon silencing program.

\section{Coevolution of Transposons and Their Control Pathways}

All sexual organisms must transmit an intact and functioning copy of their genome to offspring. To accomplish this, germline cells must be protected from transposable element mobilization that can interrupt normal gene function, compete for essential cellular localization signals (Van De Bor et al. 2005), and generate widespread genomic instability, inducing catastrophic DNA damage, 
triggering cellular checkpoints (Theurkauf et al. 2006; Klattenhoff et al. 2007) and a dramatic loss in fertility (Kidwell et al. 1977).

The threat posed by transposons comes on many fronts. Specifically, transposons are incredibly diverse in number, composition, and pattern of expression. This allows individual transposon types to fill specific niches, being expressed at different developmental stages and in particular cell types. As an extreme example, in Drosophila, the gypsy family of LTR (long terminal repeat) retrotransposon limits its expression to ovarian somatic cells that surround the germline compartment. This initially seems at odds with the imperative to expand copy number in the germline genome. However, gypsy family elements, unlike others in Drosophila, have regained features of their viral past, reconciling somatic expression and germline transmission.

Gypsy elements belong to the class of errantivirus, functionally related to human endogenous retroviruses and defined by their possession of a virally derived envelope gene (Kim et al. 1994). This allows for the packaging of gypsy RNA and protein into viral particles that can infect neighboring cells. In Drosophila, when somatic cells of the ovary fail to silence these elements, not only can this process be visualized using electron microscopy, but germline transmission and mutagenesis by gypsy elements can also be detected (Pélisson et al. 1994; Song et al. 1994, 1997; Lécher et al. 1997). In response to this apparent threat, organisms have two choices: either target the transmitted copies for destruction in the germline or silence these elements during production in the surrounding somatic cells. Drosophila appears to have adapted to regulate these elements at their source in the soma.

The piRNA-based pathway that targets gypsy in the soma has evolved unique molecular, cellular, and genomic features that distinguish it from the germline pathway (Fig. 2). First, in contrast to germline cells that express all three Piwi proteins, somatic cells use only the Piwi protein itself to combat transposon activity. Second, only one specialized, single-stranded piRNA cluster, flamenco, appears to be expressed in this niche. Molecular genetic

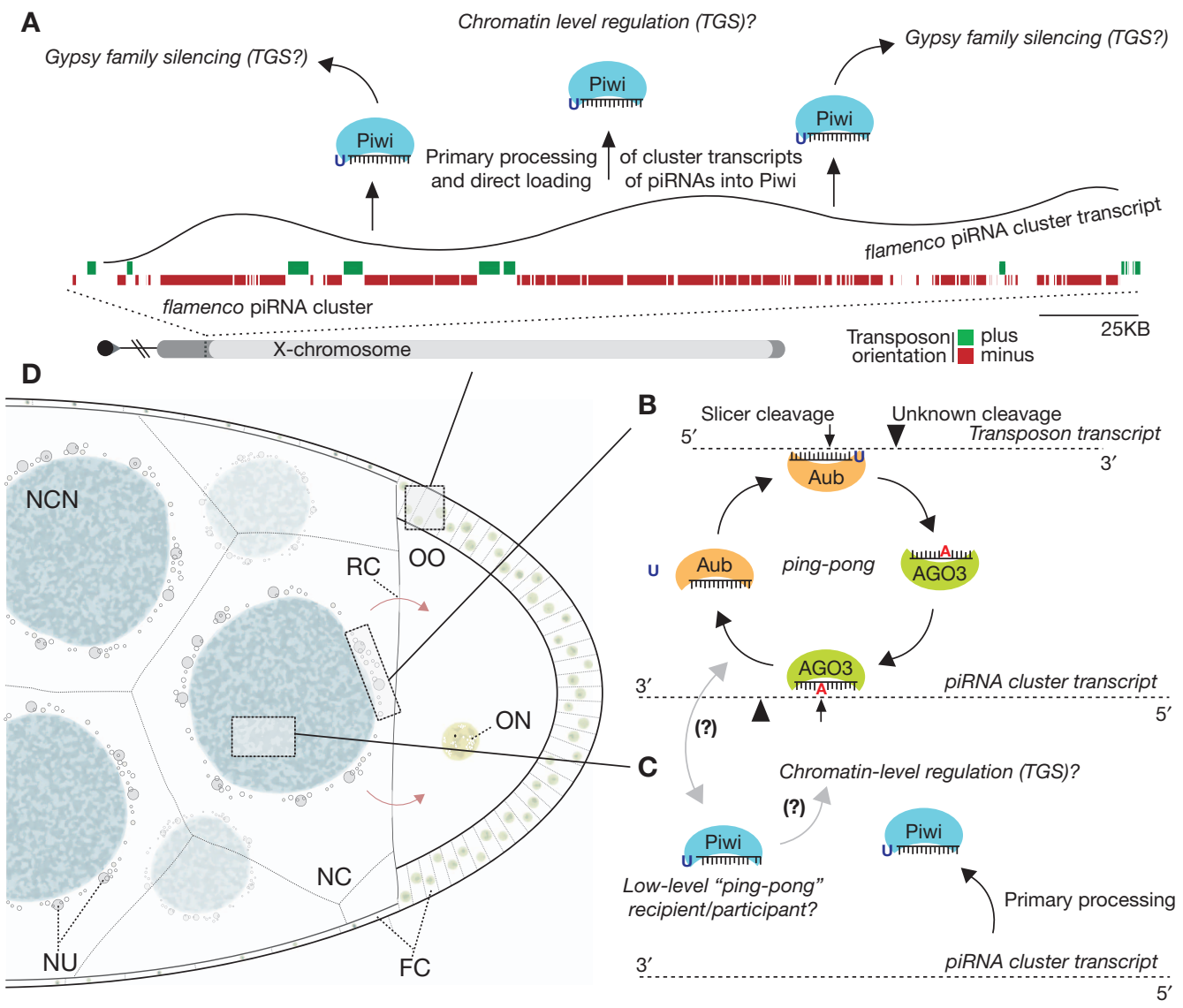

Figure 2. Models of piRNA pathway silencing in distinct tissues of the Drosophila ovary. Germline and somatic cells of the Drosophila ovary use vastly different mechanisms to combat particular transposon threats. $(A)$ In somatic cells of the ovary, flamenco cluster transcription precedes its processing to piRNAs that are directly loaded into the Piwi protein, which targets somatically expressed transposons (gypsy family) for silencing. Given Piwi's nuclear localization, regulation is likely occurring at the transcriptional level. (TGS) Transcriptional gene silencing. (B) The Aub and AGO3 proteins actively cycle in a germline-specific feed forward amplification loop to generate a potent and abundant pool of silencing-capable piRNAs. $(C)$ Piwi may act similarly in the germline as in the soma. Here, the Piwi protein may directly bind antisense, cluster-derived piRNAs to silence elements by TGS. Additionally, Piwi may serve as a low-level recipient or participant with AGO3 in the ping-pong cycle. $(D)$ Diagram of a mid/late-stage egg chamber of the Drosophila ovary. (NC) Nurse cell (germline); (NCN) nurse cell nucleus; (OO) oocyte; (ON) oocyte nucleus; (NU) nuage; (FC) follicular cell (somatic); (RC) ring canal. 
studies previously classified this locus a master regulator of gypsy family elements (Prud'homme et al. 1995; Mével-Ninio et al. 2007), and flamenco was later annotated as a prominent piRNA cluster (Brennecke et al. 2007; Malone et al. 2009). Third, biogenesis of gypsy element piRNAs requires no piRNA "ping-pong," but instead involves the processing of long flamenco transcripts into primary piRNAs (secondary being “ping-pong"-derived) (Malone et al. 2009). These are directly loaded into the Piwi protein, where they effectively guide silencing of gypsy family elements. Here, selective pressures on the orientation of transposon fragments within the cluster allow for the almost exclusive production of antisense piRNAs necessary to silence active transposon transcripts. This feature is not shared with any abundant germline clusters that instead enrich for antisense species in a manner that depends on piRNA "ping-pong."

The mechanisms of piRNA production and silencing by Piwi in somatic cells remain a mystery, although the nuclear localization of Piwi could indicate a role of chromatin-level silencing. This is supported by Piwi association with the chromatin-bound HP1 (Brower-Toland et al. 2007) and links between the Piwi protein and chromatin regulation in other tissues (Pal-Bhadra et al. 2004). Finally, the flamenco locus, found within the pericentric heterochromatin of the $\mathrm{X}$ chromosome, appears to be under positive selection, because it is identifiable at the same locus in at least two other sequenced Drosophilid species (Malone et al. 2009). Interestingly, although gypsy elements remain enriched in these putative flamencos, the individual elements present are distinct, indicating that this locus coevolves to combat the changing transposon threat in somatic cells of the Drosophila ovary.

Given this apparent pressure for piRNA clusters to maintain and combat the transposons activated in a specific tissue or cell type, it is likely that many or all clusters occupy their own spatial and temporal niches, despite presently being lumped as germline loci. Here, a cluster would become established in the genome to provide either antisense transposon transcripts for the "ping-pong" cycle or antisense primary piRNAs for Piwi. Presumably, a cluster can only act to silence elements with which it is coexpressed, and as is the case for flamenco, it also exclusively retains elements that pose a threat within the same transcriptional niche (Fig. 3). Therefore, given the need for piRNA clusters to consume active transposons for subsequent silencing and the propensity for transposons to mobilize into actively transcribed regions of the genome, the molecular coevolution of transposons and their control pathways may be linked at a transcriptional level. In mice, where gonadal maturation occurs in a more synchronized fashion, piRNA cluster expression and their targets are distinct throughout different stages of development (Aravin et al. 2007, 2008).

\section{Long- and Short-term Evolution of Transposon Silencing}

One question stemming from this work is whether the integration of a transposable element into a cluster is alone sufficient for its recognition by the pathway and silencing of active elements. By looking at active elements integrated into abundant piRNA clusters, such as the somatic flamenco and germline $42 \mathrm{AB}$, it appears that integration leads to the immediate generation of piRNAs, because piRNAs spanning insertion boundaries are detectable (data not shown). However, after insertion within a cluster, there may be a selective pressure to mutate elements away from consensus, meaning that they would lose the capacity to transcribe on their own, mobilize, or generate functional transposon proteins. In fact, most of the elements in clusters are highly diverged from an active form. That being said, there must also be a pressure to restrict element mutation from reaching a point where the sequence similarity required to target active elements is lost. This may well be an example of purifying, or stabilizing, selection, where the extremes (few mutations leaving active transposons or high mutations resulting in a loss of sequence identity) are selected against, and instead a middle ground, where both needs are satisfied, is favored. One such example holds for the $I$-element LINE (long interspersed nucleotide element) retrotransposon, where although a particular lab strain of Drosophila contains no active elements, it maintains ancient fragments within a cluster that are the same as those seen in strains that silence colonizing, active $I$ elements. This indicates some pressure to diverge but not lose even ancient transposon fragments within a cluster, a point also supported by the conservation of gypsy fragments in flamenco despite the absence of an active threat (Pélisson et al. 2007). In the case of the $I$ element, these fragments alone are insufficient to silence active elements in the lab strain but instead can only act in the presence of a maternally transmitted pool of Piwi-bound piRNAs (Brennecke et al. 2008), a point discussed in more detail below.

This sequence-level conservation of piRNAs lies in stark contrast to the miRNA pathway, which uses individual loci that are under strong selection and are transcribed to generate a single, potent, small RNA to target the regulation of specific mRNAs harboring complementary sites. These individual elements remain conserved throughout eukaryotes, despite otherwise substantial genomic divergences. In contrast, piRNA pathways use abundant piRNA molecules that tile across transposable elements. With many piRNAs diverging significantly from transposon consensus, there is the possibility that drift of sequences within piRNA clusters may be important not only to combat the evolution of transposons that already exist within a genome, but also to provide some measure of protection from horizontal transmission of elements from closely related species (Brennecke et al. 2007).

A key mystery is how the cell selects transposon and cluster transcripts to feed them into the pathway, leaving the majority of other cellular RNAs untouched. For instance, the vast majority of mRNAs, tRNAs, and rRNAs are excluded from metabolism into piRNAs, whereas the vast majority of transposon transcripts, most of which will be translated into protein just as are gene products, are funneled into the pathway. Although upward of $85 \%$ of piRNAs are generated from transposons or other repeats, a small fraction is in fact gene derived (Brennecke et al. 2007; Saito et al. 2009). In general, these are from the sense strand, indicating their direct production from the target 

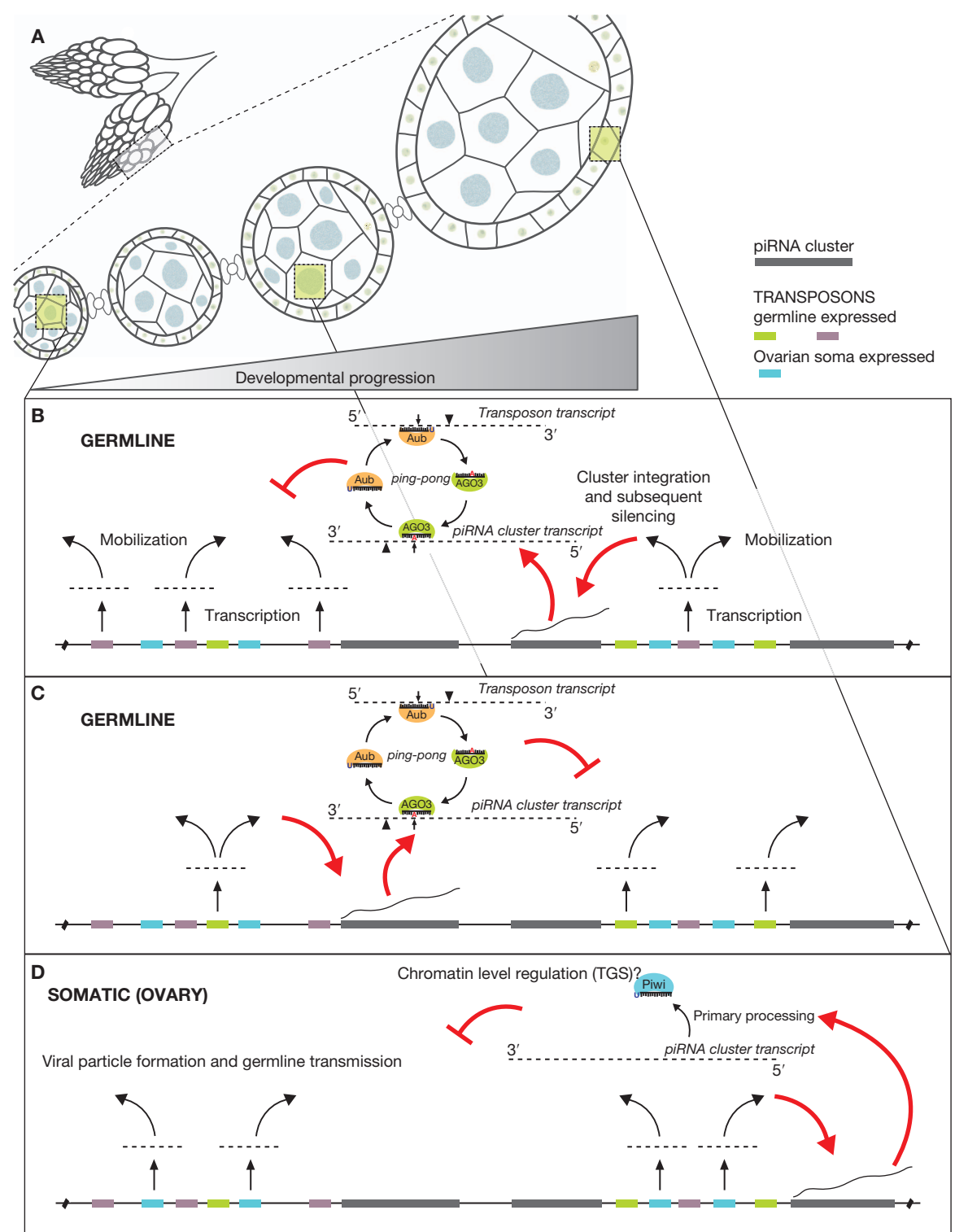

Figure 3. Model for the acquisition of piRNA cluster-based transposon control. Tissue and developmental expression of piRNA clusters could act to combat the diverse expression programs of the myriad transposons in Drosophila. (A) The Drosophila ovary is a complex tissue, representing a full spectrum of oogenesis developmental stages and containing a mixture of both germline and somatic tissues. (B) Germline-expressed transposons (here, purple) eventually mobilize into a coexpressed piRNA cluster (red arrows). This mobilization leads to the entrance of that element into a potent silencing program involving piRNA "ping-pong" and leading to the PTGS (posttranscriptional gene silencing) of active transposon transcripts. (C) Same as $B$, only now a different set of transposons (green), expressed at a distinct developmental stage, are trapped into the piRNA pathway by a separate, yet coexpressed, piRNA cluster. $(D)$ A somatic expressed cluster (flamenco) captures transposing gypsy family elements, which are transcriptionally active in somatic cells and possess the ability to package into viral particles that infect germline nuclei. However, in this case, transposition into the flameco cluster would need to occur and be selected for within the germline cells.

locus, and perhaps even from its protein-coding transcript. However, piRNA production is restricted to the $3^{\prime}$ portion of the transcript, almost exclusively from the untranslated region. Although some of these piRNAs are found in the Drosophila Aubergine and AGO3 proteins, the majority are loaded into Piwi and show no indication of having been generated via "ping-pong" (data not shown). This may indicate that the majority of genic piRNAs are being produced in somatic cells of the ovary, which is also supported by their strict genetic dependence on Piwi and their detection in cell lines with principally somatic character (Niki et al. 2006; Lau et al. 2009). Overall, these RNAs may represent a mistake, where the cell recognizes some expression or transcript feature of these few mRNAs and feeds them into a primary piRNA pathway. Otherwise, these could be representative of a bone fide regulatory mechanism, wherein these piRNAs serve a legitimate regulatory role for nontransposon RNAs. Either way, these exceptions to 
the rule may guide further investigation into the origins of transposon recognition and silencing.

\section{Other Uses of Soma-derived RNAs}

Interestingly, there is further precedence for the protection of germline integrity by somatic small RNA pathways. In Arabidopsis, the vegetative, somatic nucleus within pollen down-regulates the DNA methyltransferase DDM1, releasing transposon repression and flooding itself with active transposon transcripts (Slotkin et al. 2009). These RNAs are then processed into small interfering RNAs (siRNAs) and are transported into the developing germline nucleus, programming the RNAi machinery to suppress transposon activity. In this way, the somatic nucleus sacrifices itself for the good of the transmitted germ-cell genome. In an alternative scenario, singlecelled ciliates use RNA templates from a somatic nucleus as a target for germline-derived small RNAs. These transcripts (Lepère et al. 2008), the small RNAs (Malone et al. 2005; Mochizuki and Gorovsky 2005), and their targeting are all essential for the development of a new somatic genome within the cell (Mochizuki et al. 2002; Mochizuki and Gorovsky 2004). These examples underscore the diversity of mechanisms that eukaryotic cells use in recruiting somatically derived RNA molecules for the protection of the germline genome.

\section{Hybrid Dysgenesis, Speciation, and the piRNA Pathway}

Mating incompatibilities occur for many reasons, ranging from genital organ incongruity, to differences in chromosomal structure, and even to single-gene incompatibilities (Brideau et al. 2006; Lee et al. 2008). Although some molecular bases for mating incompatibilities between different species are well understood, new mechanisms continue to be discovered (Bayes and Malik 2009; Gerke et al. 2009). In one incompatibility phenomenon, termed "hybrid dysgenesis," severe defects in fertility are experienced in progeny from crosses between different strains of the same Drosophila species (Picard and L'Heritier 1971; Picard 1976; Kidwell et al. 1977). Here, when a wild-caught female is crossed to a lab-strain male, progeny are perfectly fertile. However, in the reciprocal cross (lab female to wild male), progeny display nearly complete infertility, often accompanied by significant gonadal atrophy (Fig. 4). Early work linked these fertility and developmental failures to the inability of dysgenic progeny to silence a single transposable element that had colonized and was subsequently brought under control only in the wild strain (Pélisson 1981; Kidwell 1983; Bucheton et al. 1984; Chambeyron and Bucheton 2005). Despite their differing fertilities, progeny of the dysgenic (sterile) and nondysgenic (fertile) crosses are genetically identical. It was therefore proposed that mothers must grant a nongenetic factor that allows progeny to silence transposon expression (Bregliano et al. 1980). Recent work has shown that maternally inherited Piwi proteins and their bound piRNAs are the essential factor mediating this germline transposon silencing, underlying the
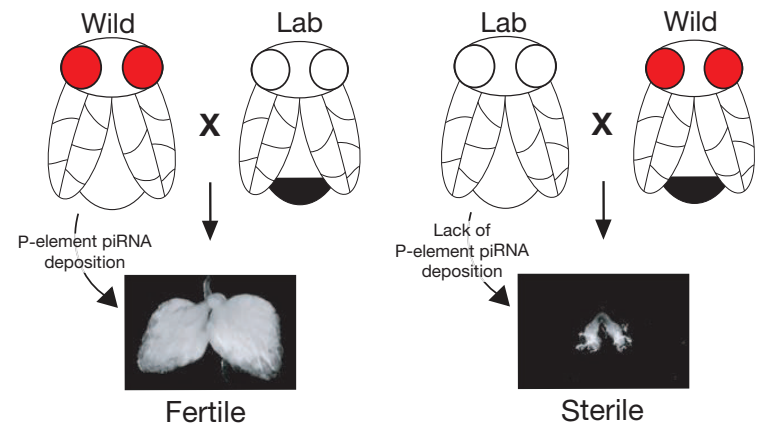

Figure 4. P-element hybrid dysgenesis in Drosophila. Certain crosses between wild (red eyes) and lab-maintained (white eyes) strains of Drosophila melanogaster produce sterile offspring. This sterility is caused by the naïveté and inability of the lab strain to silence a single transposable element (here, the P element) that has colonized the wild strain. Here, piRNAs serve as the epigenetic factor deposited by mothers (light abdomen) to facilitate the silencing of transposons in progeny (males, dark abdomen). A severe defect in ovarian development, including necrosis, accompanies dysgenesis.

phenomenon of hybrid dysgenesis (Blumenstiel and Hartl 2005; Brennecke et al. 2008).

Mechanistically, maternally deposited piRNAs are required to kick-start the "ping-pong" transposon control pathway in developing and adult progeny (Brennecke et al. 2008). At least for some transposons, "ping-pong" requires priming by maternally inherited piRNAs because their absence, even in the presence of sense and antisense transposon transcripts, causes dual failures in piRNA accumulation and element silencing. This requirement creates a conundrum as to what comes first: "ping-ponging" piRNAs or the maternally deposited piRNAs required to start "pingpong." In one case, it takes $\sim 15$ generations for a Drosophila strain devoid of active $I$ elements to gain control over challenge by this retrotransposon (Pélisson and Bregliano 1987). Presumably, this is mediated by the gradual buildup of both $I$-element copy number and the piRNAs required to silence further transposon expression. Interestingly, the lab strain, which contains no active copies, does harbor ancient I-element remnants in the $42 \mathrm{AB}$ piRNA cluster; however, these alone do not possess any significant silencing capacity. Regardless, it remains unclear as to whether an initial step in the adaptation to control of a new element first occurs by piRNA-based silencing in the ovary of an adult animal or whether a threshold must first be met, with the (spontaneous) deposition of sufficient piRNAs to prime control. Either way, it seems clear that engagement by the pathway must be preceded by the transposition of an element into a piRNA cluster.

From a population perspective, this may have implications for speciation. If we consider a scenario wherein two separated populations acquire different spectra of active elements and active resistance, reciprocal hybrid incompatibilities could result. This would in effect cause reproductive isolation and the first step on the road to the creation of new species. The degree to which this course might be inevitable would depend on the strength of the incompatibility. Even particular strains of different Dro- 
sophila species (melanogaster and simulans) can be mated to each other to generate some viable and fertile offspring (Davis et al. 1996). This effect is not fully penetrant, can show a gender bias in viable offspring, and can be attributed to several processes, including single-gene incompatibilities. However, D. simulans contains at least one transposable element, mariner, which is absent from D. melanogaster (Maruyama and Hartl 1991), further supporting the possibility that transposon differences can contribute, at least at some level, to speciation mating incompatibilities (Rose and Doolittle 1983). Regardless, the phenomenon of hybrid dysgenesis presents an empirically validated phenomenon by which transposon-based mating incompatibilities are apparent within a single generation and likewise may represent a substantial evolutionary force. In this model, the piRNA pathway and its design as a supremely adaptable system is likely critical for maintaining species integrity.

\section{CONCLUSION}

Elaborate and specialized small RNA pathways of transposon regulation have developed in diverse organisms and in a multitude of tissues types. However, our understanding of the molecular basis of the acquisition to and adaptation of transposon control mechanisms remains illusive on many levels. First, an organism must have a means of recognizing invading elements as foreign and likewise mark these for silencing. This may very well occur through a single, heritable insertion of a transposon into a piRNA cluster, leading to the initial production of small RNAs and likewise offering the cell a means by which to silence additional elements of the same type and sequence. However, this almost certainly cannot explain the entirety of adaptation to transposon control because there is a clear and essential role for deposited Piwi proteins/piRNAs in kick-starting an effective "ping-pong" biogenesis and silencing program for some elements. Regardless, piRNA clusters no doubt provide a means to capture new transposon threats and to retain a memory of transposon challenge.

One mechanism by which transposon expression and mobilization are combated by the cell would be selecting coexpression of specific piRNA clusters and elements at similar developmental stages (see Fig. 3). Once an element lands in a cluster with which it is coexpressed, that transposon and its control mechanisms will be transcriptionally linked. This implies a diversity of cluster expression patterns that has yet to be investigated. Some support for this model comes from the existence of a potent piRNA silencing pathway in somatic cells of the Drosophila ovary, which uses a single piRNA cluster, flamenco, in the regulation of gypsy family elements (Malone et al. 2009).

An important observation involving the molecular evolution of piRNA pathways involves not the adaptation to control, but simply the conservation of particular loci to combat various invading elements. Here, using the flamenco locus as a model of piRNA cluster and heterochromatic selection, it appears that this tract of pericentric heterochromatin has served as a catalog of the specific somatic transposon threat in several distinct species. Interestingly, the type, but not the individual elements occupying these putative flamenco clusters, is conserved. This indicates that a heterochromatic domain is selectively maintained by populations with the functional capacity to serve presumably similar roles in preserving a memory of somatic transposon expression. Given the selective advantage to maintain other specified "heterochromatic" loci, such as centromeres and pericentric arrays, it seems feasible that there are diverse and distinct evolutionary pressures acting broadly on both euchromatic and heterochromatic sequences of the genome.

Many questions remain about the relationship between host genomes and colonizing transposable elements, most of which relate to either the silencing mechanisms themselves or the adaptation of populations to control invading elements. Organisms have developed a defense strategy that successfully balances both the deleterious consequences of transposon mobilization and the benefits for genome evolution and adaptive control of future invasions. Either way, small RNA-based pathways represent a key transition by organisms to engage in an elegant and adaptive battle against the selfish needs of transposable elements.

\section{ACKNOWLEDGMENTS}

We thank members of the Hannon Laboratory for helpful discussion, especially Julius Brennecke and Ralph Burgess. C.D.M. is a Beckman fellow of the Watson School of Biological Sciences and is supported by a National Science Foundation graduate research fellowship. This work was supported in part by grants from the National Institutes of Health to G.J.H. and a kind gift from Kathryn W. Davis (G.J.H.).

\section{REFERENCES}

Aravin AA, Naumova NM, Tulin AV, Vagin VV, Rozovsky YM, Gvozdev VA. 2001. Double-stranded RNA-mediated silencing of genomic tandem repeats and transposable elements in the $D$. melanogaster germline. Curr Biol 11: 1017-1027.

Aravin AA, Lagos-Quintana M, Yalcin A, Zavolan M, Marks D, Snyder B, Gaasterland T, Meyer J, Tuschl T. 2003. The small RNA profile during Drosophila melanogaster development. Dev Cell 5: 337-350.

Aravin A, Gaidatzis D, Pfeffer S, Lagos-Quintana M, Landgraf P, Iovino N, Morris P, Brownstein MJ, Kuramochi-Miyagawa S, Nakano T, et al. 2006. A novel class of small RNAs bind to MILI protein in mouse testes. Nature 442: 203-207.

Aravin AA, Sachidanandam R, Girard A, Fejes-Toth K, Hannon GJ. 2007. Developmentally regulated piRNA clusters implicate MILI in transposon control. Science 316: 744-747.

Aravin AA, Sachidanandam R, Bourc'his D, Schaefer C, Pezic D, Toth KF, Hannon GJ. 2008. A piRNA pathway primed by individual transposons is linked to de novo DNA methylation in mice. Mol Cell 31: 785-799.

Baudry C, Malinsky S, Restituito M, Kapusta A, Rosa S, Meyer E, Bétermier M. 2009. PiggyMac, a domesticated piggyBac transposase involved in programmed genome rearrangements in the ciliate Paramecium tetraurelia. Genes Dev 23: 2478-2483.

Bayes JJ, Malik HS. 2009. Altered heterochromatin binding by a hybrid sterility protein in Drosophila sibling species. Science 326: $1538-1541$. 
Belgnaoui SM, Gosden RG, Semmes OJ, Haoudi A. 2006. Human LINE-1 retrotransposon induces DNA damage and apoptosis in cancer cells. Cancer Cell Int 6: 13.

Blumenstiel JP, Hartl DL. 2005. Evidence for maternally transmitted small interfering RNA in the repression of transposition in Drosophila virilis. Proc Natl Acad Sci 102: 15965-15970.

Bregliano JC, Picard G, Bucheton A, Pélisson A, Lavige JM, L'Heritier P. 1980. Hybrid dysgenesis in Drosophila melanogaster. Science 207: 606-611.

Brennecke J, Aravin AA, Stark A, Dus M, Kellis M, Sachidanandam R, Hannon GJ. 2007. Discrete small RNA-generating loci as master regulators of transposon activity in Drosophila. Cell 128: $1089-1103$.

Brennecke J, Malone CD, Aravin AA, Sachidanandam R, Stark A, Hannon GJ. 2008. An epigenetic role for maternally inherited piRNAs in transposon silencing. Science 322: 1387-1392.

Brideau NJ, Flores HA, Wang J, Maheshwari S, Wang X, Barbash DA. 2006. Two Dobzhansky-Muller genes interact to cause hybrid lethality in Drosophila. Science 314: 1292-1295.

Brower-Toland B, Findley SD, Jiang L, Liu L, Yin H, Dus M, Zhou P, Elgin SC, Lin H. 2007. Drosophila PIWI associates with chromatin and interacts directly with HP1a. Genes Dev 21: 2300-2311.

Bucheton A, Paro R, Sang HM, Pélisson A, Finnegan DJ. 1984. The molecular basis of I-R hybrid dysgenesis in Drosophila melanogaster: Identification, cloning, and properties of the I factor. Cell 38: 153-163.

Chambeyron S, Bucheton A. 2005. I elements in Drosophila: In vivo retrotransposition and regulation. Cytogenet Genome Res 110: $215-222$.

Cox DN, Chao A, Baker J, Chang L, Qiao D, Lin H. 1998. A novel class of evolutionarily conserved genes defined by piwi are essential for stem cell self-renewal. Genes Dev 12: 3715-3727.

Cox DN, Chao A, Lin H. 2000. piwi encodes a nucleoplasmic factor whose activity modulates the number and division rate of germline stem cells. Development 127: 503-514.

Davis AW, Roote J, Morley T, Sawamura K, Herrmann S, Ashburner M. 1996. Rescue of hybrid sterility in crosses between $D$. melanogaster and D. simulans. Nature 380: 157-159.

Demerec M. 1926a. Reddish - A frequently "mutating" character in Drosophila virilis. Proc Natl Acad Sci 12: 11-16.

Demerec M. 1926b. Miniature- $\alpha$ - A second frequently mutating character in Drosophila virilis. Proc Natl Acad Sci 12: 687-690.

Dimitri P, Bucheton A. 2005. I element distribution in mitotic heterochromatin of Drosophila melanogaster reactive strains: Identification of a specific site which is correlated with the reactivity levels. Cytogenet Genome Res 110: 160-164.

Elbashir SM, Lendeckel W, Tuschl T. 2001. RNA interference is mediated by 21- and 22-nucleotide RNAs. Genes Dev 15: 188 200

Esnault C, Maestre J, Heidmann T. 2000. Human LINE retrotransposons generate processed pseudogenes. Nat Genet 24: 363 367

Gerke J, Lorenz K, Cohen B. 2009. Genetic interactions between transcription factors cause natural variation in yeast. Science 323: 498-501.

Gilbert N, Lutz-Prigge S, Moran JV. 2002. Genomic deletions created upon LINE-1 retrotransposition. Cell 110: 315-325.

Girard A, Sachidanandam R, Hannon GJ, Carmell MA. 2006. A germline-specific class of small RNAs binds mammalian Piwi proteins. Nature 442: 199-202.

Gunawardane LS, Saito K, Nishida KM, Miyoshi K, Kuwamura Y, Nagami T, Siomi H, Siomi MC. 2007. A slicer-mediated mechanism for repeat-associated siRNA $5^{\prime}$ end formation in Drosophila. Science 315: 1587-1590.

Hannon GJ. 2002. RNA interference. Nature 418: 244-251.

Houwing S, Kamminga LM, Berezikov E, Cronembold D, Girard A, van den Elst H, Filippov DV, Blaser H, Raz E, Moens CB, et al. 2007. A role for Piwi and piRNAs in germ cell maintenance and transposon silencing in zebrafish. Cell 129: 69-82.

Houwing S, Berezikov E, Ketting RF. 2008. Zili is required for germ cell differentiation and meiosis in zebrafish. EMBOJ 27: $2702-2711$.
Kaminker JS, Bergman CM, Kronmiller B, Carlson J, Svirskas R, Patel S, Frise E, Wheeler DA, Lewis SE, Rubin GM, et al. 2002. The transposable elements of the Drosophila melanogaster euchromatin: A genomics perspective. Genome Biol 3: RESEARCH0084.

Kazazian HH. 2004. Mobile elements: Drivers of genome evolution. Science 303: 1626-1632.

Kidwell MG. 1983. Evolution of hybrid dysgenesis determinants in Drosophila melanogaster. Proc Natl Acad Sci 80: 1655-1659.

Kidwell MG, Kidwell JF, Sved JA. 1977. Hybrid dysgenesis in Drosophila melanogaster: A syndrome of aberrant traits including mutation, sterility and male recombination. Genetics 86: 813-833.

Kim A, Terzian C, Santamaria P, Pélisson A, Prud'homme N, Bucheton A. 1994. Retroviruses in invertebrates: The gypsy retrotransposon is apparently an infectious retrovirus of Drosophila melanogaster. Proc Natl Acad Sci 91: 1285-1289.

Klattenhoff C, Bratu DP, McGinnis-Schultz N, Koppetsch BS, Cook HA, Therkauf WE. 2007. Drosophila rasiRNA pathway mutations disrupt embryonic axis specification through activation of an ATR/Chk2 DNA damage response. Dev Cell 12: 4555.

Lau NC, Seto AG, Kim J, Kuramochi-Miyagawa S, Nakano T, Bartel DP, Kingston RE. 2006. Characterization of the piRNA complex from rat testes. Science 313: 363-367.

Lau NC, Robine N, Martin R, Chung WJ, Niki Y, Berezikov E, Lai EC. 2009. Abundant primary piRNAs, endo-siRNAs, and microRNAs in a Drosophila ovary cell line. Genome Res 19: 1776-1785.

Lécher P, Bucheton A, Pélisson A. 1997. Expression of the Drosophila retrovirus gypsy as ultrastructurally detectable particles in the ovaries of flies carrying a permissive flamenco allele. $J$ Gen Virol 78: 2379-2388.

Lee HY, Chou JY, Cheong L, Chang NH, Yang SY, Leu JY. 2008. Incompatibility of nuclear and mitochondrial genomes causes hybrid sterility between two yeast species. Cell 135: 10651073.

Lepère G, Bétermier M, Meyer E, Duharcourt S. 2008. Maternal noncoding transcripts antagonize the targeting of DNA elimination by scanRNAs in Paramecium tetraurelia. Genes Dev 22: $1501-1512$.

Li C, Vagin VV, Lee S, Xu J, Ma S, Xi H, Seitz H, Horwich MD, Syrzycka M, Honda BM, et al. 2009. Collapse of germline piRNAs in the absence of Argonaute 3 reveals somatic piRNAs in flies. Cell 137: 509-521.

Malone CD, Hannon GJ. 2009. Small RNAs as guardians of the genome. Cell 136: 656-668.

Malone CD, Anderson AM, Motl JA, Rexer CH, Chalker DL. 2005. Germ line transcripts are processed by a Dicer-like protein that is essential for developmentally programmed genome rearrangements of Tetrahymena thermophila. Mol Cell Biol 25: 9151-9164.

Malone CD, Brennecke J, Dus M, Stark A, McCombie WR, Sachidanandam R, Hannon GJ. 2009. Specialized piRNA pathways act in germline and somatic tissues of the Drosophila ovary. Cell 137: 522-535.

Marin L, Lehmann M, Nouaud D, Izaabel H, Anxolabéhère D, Ronsseray S. 2000. P-element repression in Drosophila melanogaster by a naturally occurring defective telomeric $\mathrm{P}$ copy. Genetics 155: 1841-1854.

Maruyama K, Hartl DL. 1991. Evolution of the transposable element mariner in Drosophila species. Genetics 128: 319-329.

McClintock B. 1950. The origin and behavior of mutable loci in maize. Proc Natl Acad Sci 36: 344-355.

Mével-Ninio M, Pélisson A, Kinder J, Campos AR, Bucheton A. 2007. The flamenco locus controls the gypsy and ZAM retroviruses and is required for Drosophila oogenesis. Genetics 175: $1615-1624$.

Miller WJ, Hagemann S, Reiter E, Pinsker W. 1992. P-element homologous sequences are tandemly repeated in the genome of Drosophila guanche. Proc Natl Acad Sci 89: 4018-4022.

Mochizuki K, Gorovsky MA. 2004. Small RNAs in genome rearrangement in Tetrahymena. Curr Opin Genet Dev 14: 181-187. 
Mochizuki K, Gorovsky MA. 2005. A Dicer-like protein in Tetrahymena has distinct functions in genome rearrangement, chromosome segregation, and meiotic prophase. Genes Dev 19: $77-89$.

Mochizuki K, Fine NA, Fujisawa T, Gorovsky MA. 2002. Analysis of a piwi-related gene implicates small RNAs in genome rearrangement in Tetrahymena. Cell 110: 689-699.

Niki Y, Yamaguchi T, Mahowald AP. 2006. Establishment of stable cell lines of Drosophila germ-line stem cells. Proc Natl Acad Sci 103: 16325-16330.

Pal-Bhadra M, Leibovitch BA, Gandhi SG, Rao M, Bhadra U, Birchler JA, Elgin SC. 2004. Heterochromatic silencing and HP1 localization in Drosophila are dependent on the RNAi machinery. Science 303: 669-672.

Pélisson A. 1981. The I-R system of hybrid dysgenesis in Drosophila melanogaster: Are I factor insertions responsible for the mutator effect of the I-R interaction? Mol Gen Genet 183: 123-129.

Pélisson A, Bregliano JC. 1987. Evidence for rapid limitation of the I element copy number in a genome submitted to several generations of I-R hybrid dysgenesis in Drosophila melanogaster. Mol Gen Genet 207: 306-313.

Pélisson A, Song SU, Prud'homme N, Smith PA, Bucheton A, Corces VG. 1994. Gypsy transposition correlates with the production of a retroviral envelope-like protein under the tissuespecific control of the Drosophila flamenco gene. EMBOJ 13: 4401-4411.

Pélisson A, Payen-Groschêne G, Terzian C, Bucheton A. 2007. Restrictive flamenco alleles are maintained in Drosophila melanogaster population cages, despite the absence of their endogenous gypsy retroviral targets. Mol Biol Evol 24: 498504.

Picard G. 1976. Non-Mendelian female sterility in Drosophila melanogaster: Hereditary transmission of I factor. Genetics 83: 107-123.

Picard G, L'Heritier P. 1971. A maternally inherited factor inducing sterility in D. melanogaster. Drosophila Inf Serv 46: 54.

Prud'homme N, Gans M, Masson M, Terzian C, Bucheton A. 1995. Flamenco, a gene controlling the gypsy retrovirus of Drosophila melanogaster. Genetics 139: 697-711.

Reinhart BJ, Bartel DP. 2002. Small RNAs correspond to centromere heterochromatic repeats. Science 297: 1831.

Ronsseray S, Lehmann M, Anxolabéhère D. 1991. The maternally inherited regulation of $\mathrm{P}$ elements in Drosophila melanogaster can be elicited by two $\mathrm{P}$ copies at cytological site $1 \mathrm{~A}$ on the $\mathrm{X}$ chromosome. Genetics 129: 501-512.

Ronsseray S, Marin L, Lehmann M, Anxolabéhère D. 1998. Repression of hybrid dysgenesis in Drosophila melanogaster by combinations of telomeric P-element reporters and naturally occurring P elements. Genetics 149: 1857-1866.

Rose MR, Doolittle WF. 1983. Molecular biological mechanisms of speciation. Science 220: 157-162.

Saito K, Inagaki S, Mituyama T, Kawamura Y, Ono Y, Sakota E, Kotani H, Asai K, Siomi H, Siomi MC. 2009. A regulatory circuit for piwi by the large Maf gene traffic jam in Drosophila. Nature 461: 1296-1299.

Simonelig M, Bazin C, Pélisson A, Bucheton A. 1988. Transposable and nontransposable elements similar to the I factor involved in inducer-reactive (IR) hybrid dysgenesis in Drosophila melanogaster coexist in various Drosophila species. Proc Natl Acad Sci 85: 1141-1145.

Slotkin RK, Martienssen R. 2007. Transposable elements and the epigenetic regulation of the genome. Nat Rev Genet 8: 272-285.

Slotkin RK, Vaughn M, Borges F, Tanurdzić, Becker JD, Feijó JA, Martienssen RA. 2009. Epigenetic reprogramming and small RNA silencing of transposable elements in pollen. Cell 136: 461-472.

Song SU, Gerasimova T, Kurkulos M, Boeke JD, Corces VG. 1994. An env-like protein encoded by a Drosophila retroelement: Evidence that gypsy is an infectious retrovirus. Genes Dev 8: 2046-2057.

Song SU, Kurkulos M, Boeke JD, Corces VG. 1997. Infection of the germ line by retroviral particles produced in the follicle cells: A possible mechanism for the mobilization of the gypsy retroelement of Drosophila. Development 124: 2789-2798.

Symer DE, Connelly C, Szak ST, Caputo EM, Cost GJ, Parmigiani G, Boeke JD. 2002. Human 11 retrotransposition is associated with genetic instability in vivo. Cell 110: 327-338.

Theurkauf WE, Klattenhoff C, Bratu DP, McGinnis-Schultz N, Koppetsch BS, Cook HA. 2006. rasiRNAs, DNA damage, and embryonic axis specification. Cold Spring Harbor Symp Quant Biol 71: 171-180.

Vagin VV, Sigova A, Li C, Seitz H, Gvozdev V, Zamore PD. 2006. A distinct small RNA pathway silences selfish genetic elements in the germline. Science 313: 320-324.

Van De Bor V, Hartswood E, Jones C, Finnegan D, Davis I. 2005. gurken and the $I$ factor retrotransposon RNAs share common localization signals and machinery. Dev Cell 9: 51-62.

Volpe TA, Kidner C, Hall IM, Teng G, Grewal SI, Martienssen RA. 2002. Regulation of heterochromatic silencing and histone H3 lysine-9 methylation by RNAi. Science 297: 18331837.

White SE, Habera LF, Wessler SR. 1994. Retrotransposons in the flanking regions of normal plant genes: A role for copia-like elements in the evolution of gene structure and expression. Proc Natl Acad Sci 91: 11792-11796. 


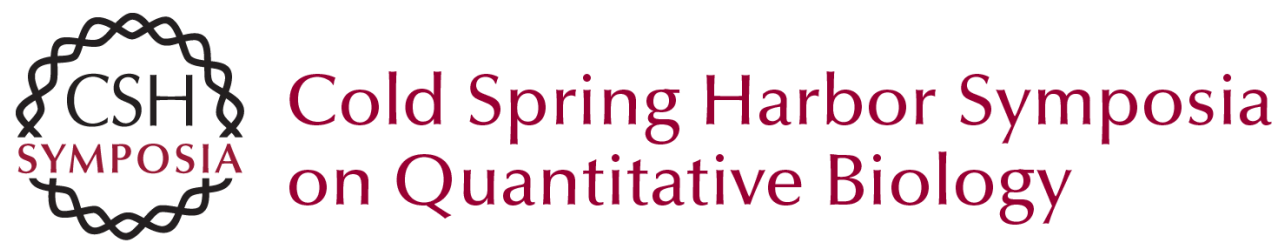

\section{Molecular Evolution of piRNA and Transposon Control Pathways in Drosophila}

C.D. Malone and G.J. Hannon

Cold Spring Harb Symp Quant Biol 2009 74: 225-234 originally published online May 7, 2010 Access the most recent version at doi:10.1101/sqb.2009.74.052

References This article cites 78 articles, 36 of which can be accessed free at: http://symposium.cshlp.org/content/74/225.full.html\#ref-list-1

\section{License}

Email Alerting Service top right corner of the article or click here. 